\title{
O RESPEITO A PRIVACIDADE E O TRATAMENTO DE DADOS PESSOAIS SENSÍVEIS NO CENÁRIO DE PANDEMIA
}

\section{ARTIGO ORIGINAL}

MOREIRA, Roziane dos Santos ${ }^{1}$

LOPES, Luana da Cunha ${ }^{2}$

MOREIRA, Roziane dos Santos. LOPES, Luana da Cunha. O respeito a privacidade e o tratamento de dados pessoais sensíveis no cenário de pandemia. Revista Científica Multidisciplinar Núcleo do Conhecimento. Ano 05, Ed. 10, Vol. 16, pp. 6880. Outubro de 2020. ISSN: 2448-0959, Link de acesso: https://www.nucleodoconhecimento.com.br/lei/dados-pessoais

\section{RESUMO}

O uso da internet facilitou o acesso a informação, mas em contrapartida expõem os dados pessoais dos usuários para o mundo sem o devido respeito de alguns direitos fundamentais. Diante da ausência da regulamentação das relações entre usuários e os sites da internet surge a Lei 13.709/19, Lei Geral de Proteção de Dados (LGPD). Então, como o ordenamento jurídico brasileiro garante a eficácia da privacidade dos dados pessoais e sensíveis em meio a pandemia? O objetivo do estudo é analisar a proteção dos dados pessoais e sensíveis no cenário de pandemia. A metodologia foi de abordagem qualitativa e através de estudos bibliográficos de livros, artigos e documentos jurídicos. O Supremo Tribunal Federal durante a pandemia decidiu

\footnotetext{
${ }^{1}$ Pós-graduada em Atividade Física e Saúde, graduada em Licenciatura Plena em Educação Física e Acadêmica do $9^{\circ}$ período em Bacharelado em Direito.

2 Orientadora. Cursando Mestrado Profissional em Ciências das Religiões, Especialista em Docência Superior e Direito Penal e Processo Penal, graduação em Bacharelado em Direito e atualmente professora no ensino superior.
} 
assegurar a proteção de dados pessoais. Portanto, é importante que se estabeleça uma cultura de proteção de dados pessoais e dados de sensíveis no Brasil.

Palavras-Chave: Privacidade, pandemia, dados pessoais.

\section{INTRODUÇÃO}

O avanço da tecnologia facilitou o acesso à informação, principalmente, por meio da internet que hoje é utilizada por grande parte da população mundial. Tal fato, revelou a necessidade de garantias de alguns direitos no âmbito virtual, pois existe um desequilíbrio de poderes entre os possuidores de dados pessoais e os titulares dos dados.

O direito da personalidade, alicerçado no Código Civil Brasileiro e na Constituição Federal, pugnam pela proteção do direito da personalidade, contemplando a privacidade, como direito essencial a qualidade de vida das pessoas, frente às perspectivas individuais e ainda frente a coletividade.

Segundo Feraz Júnior (1993), a privacidade está aliada ao princípio da exclusividade, onde ocorrer uma disposição de informações entres as partes, da qual estas não pode ser repassada sem consentimento, a terceiros. Sendo umas das primeiras leis, no Brasil, a prever mecanismos e instrumentos legais e técnicos para a proteção do sigilo dos dados armazenado foi, assim observado, na Lei $n^{0} 7.232$, de 1984, que dispõe sobre a Política Nacional da Informação.

Além do valor dos dados pessoais o estado de saúde das pessoas vem sendo objeto de interesse nacional. Antes da pandemia, informações sobre quadro clínico de uma pessoa era interesse somente de familiares ou pessoas próximas, agora a curiosidade de saber quem está infectado pelo covid-19 e estágio da doença virou uma busca quase que obrigatória pela população.

A Lei $n^{\circ} 13.709$, que é a Lei Geral de Proteção de Dados Pessoais (LGPD) elenca dados sensíveis nas áreas da saúde como, por exemplo, a tutela da saúde, do procedimento realizado por profissionais da área da saúde ou por entidades sanitárias 
que são abraçados pelo direito de privacidade. Atualmente, importância do tema pode ser observada quando Presidente da República do Brasil foi obrigado os resultados de exames.

Diante dessa situação, de conflito entre interesse coletivo e individual, devemos ressaltar o interesse que devem prevalecer e as responsabilidades das instituições. Sem deixar de assegurar a segurança da saúde coletiva e individual com ponderações, já que, a LGPD entrou vigor e o direito à privacidade do estado de saúde deve ser preservado. Então cabe a nós questionar como o ordenamento jurídico brasileiro pode garantir a eficácia da privacidade dos dados pessoais e sensíveis em meio a pandemia?

O consentimento do titular dos dados é requisito principal quando se trata de dados de saúde para definir a forma de tratamento de dados, ou seja, as informações serão ou não confidenciais. Sendo a subjetividade do indivíduo que irá determinar a privacidade. A LGPD, dá ao titular o direito de corrigir dados, anonimizar dados, bloquear ou até mesmo eliminar dados pessoais que julgue desnecessário.

Essa temática tem a seu favor a atualização do debate sobre a LGPD no cenário de pandemia, onde houve o aumento de uso da internet, e que no meio de incertezas busca-se informações sobre o estado de saúde das pessoas. Portanto essa temática valoriza o direito fundamental do sigilo dos seus dados, como estado de saúde, e a privacidade da vida dos indivíduos

A LGPD, propõe garantir o respeito à privacidade e acabar com o mercado de dados pessoais para os mais diversos fins sem a autorização do usuário. No seu texto amplia as informações sobre a indivíduo que merece sigilo. Os dados pessoais e dados sensíveis são uma parcela da individualidade de uma pessoa sendo estas informações que irá diferenciar e manter um ser como único. Então objetiva-se com essa pesquisa analisar as garantias de proteção dos dados sobre a saúde, elencados na Lei 13.709/ 18, Lei Geral de Proteção de Dados, no cenário de pandemia. 


\section{METODOLOGIA}

A pesquisa foi baseada no método científico e como abordagem qualitativa afim de manter descrição do tema. Para isso a pesquisa será através de estudos bibliográfico que tem como base os livros e artigos científicos, além de teorias doutrinarias que já foram estudadas e debatidas por outros autores (SEVERINO, 2013).

O embasamento metodológico foi de suma relevância para a construção do presente trabalho, haja vista que através dos fundamentos da metodologia o trabalho se desenvolverá com grande êxito. Na pesquisa foi utilizado instrumentos bibliográfico fundamentais e suficientes para a construção do presente trabalho.

Essa ferramenta de estudos foi escolhida devido ao caráter hordiendo do tema que requer acompanhamento de decretos, decisões de tribunais, diariamente, para que esse trabalho possa contribuir com o debate do tema. A coleta dos dados foi através de leitura de livros, artigos científicos, matérias de jornais digitais, relatórios, leis, medidas provisórias e julgados dos tribunais sobre o tema.

Foram analisados os textos publicados na rede mundial de computadores sobre a lei de proteção de dados bem como artigos científicos que abordam como tema o respeito privacidade, o sigilo de dados pessoais. Além de reportagens e estudos publicados sobre os dados atuais da situação de calamidade pública provocado pelo covid-19 e a influência da pandemia na vigência da a lei 13.709/2018. Portanto os autores que tratam desta temática serão objeto de estudos.

\section{RESULTADOS}

Segundo Brasil Lei n 8.080 (1990), legitimar a coleta e uso de informações pessoais pelo sistema de saúde. Em geral, essas informações permitem a produção de políticas pública na saúde para uma melhor qualidade de vida e redução de riscos ao adoecimento da população. Contudo, a rede de saúde não possui meio que possa manter os dados dos pacientes em segurança podendo ser alvo fácil. 
A LGPD em seu texto jurídico deixa claro a intenção de aumentar a segurança de dados confidenciais onde dados clínicos devem ser compartilhados entre hospitais, clínicas e laboratórios somente com o consentimento do paciente. E caso, seja autorizado os dados devem ser criptografados, tal exigência da lei, exigem uma estruturação de equipamentos.

Um dos primeiros casos de vazamento de dados sobre saúde aconteceu no sistema de saúde do Brasil, em 2017, por meio do Cadastro do Cartão Nacional de Saúde (CNS) que passou informações como Cadastro da Pessoa Física (CPF) e dados sobre a saúde de brasileiro para empresas nortes américas sem o consentimento de 120 milhões de pessoas, violando dessa forma a vida privada de milhões de pessoas e 0 mais preocupante sem nenhuma punição a divulgação do que aconteceu.

Como a chegada do vírus no Brasil as autoridades e a população já conheciam algumas medidas de prevenção, forma de contágio, e o grandes números de mortes pelo mundo. Diante dessas informações o Poder Público determinou medidas relacionada a saúde, ao comércio e aos serviços, além de estabelecendo o estado de calamidade pública segundo Brasil, Decreto Legislativo №6, 2020.

O aumento do uso da internet, na pandemia, deixa o assunto ainda mais relevante a necessidade de estabelecer uma cultura de privacidade, já que o fluxo de comunicação digital se tornou uma necessidade de primeira linha na vida das pessoas durante o período de isolamento social. Zumas (2019), sobre a divulgação do Relatórios de Tendência de Mobilidade realizado pela Google que mostrava os pontos de aglomeração de pessoas, relata a indignação e a exigência da sua privacidade.

Como o estado de calamidade o Poder Executivo através de medida provisória de $\mathrm{n}^{\circ}$ 954 de 17 de abril de 2020, estabelece que a prestadora de serviços de telefonia compartilhe dados de clientes com a Instituto Brasileiro de Geografia e Estatística IBGE, durante a situação emergencial provocado pelo coronavírus. 


\section{DISCUSSÃO}

O empenho para proteção dos dados pessoais iniciou em 2016 no legislativo, com o Projeto de Lei Federal n.5.276/2016, na intenção de ser célere a aprovação. Mas devido à instabilidade política partidária foi retirada da urgência do legislativo (BOLESINA E DIAS, 2017). Enquanto autoridade detentoras dos armazenamentos de dados pessoas pessoais e de saúde transmitem informações sobre dados de saúde dos cidadãos brasileiros a outro país sem consentimento dos seus titulares e sem divulgação da finalidade dessa transação de informação.

Barbosa e Silva (2019) diz que os dados pessoais identificador são informações que particularizam, automaticamente, uma pessoa, o nome, número de registro, fotografia... etc. Em contrapartida os dados pessoais identificáveis são informações que precisam de uma análise ou um tratamento para conseguir identificar alguém, além de outras informações para realizar cruzamento e detectar uma pessoa.

A lei traz uma terminologia de dados pessoais que merecem ainda mais restrição de divulgação. São os dados pessoais sensíveis que são informações ainda mais especifica do indivíduo de forma sociológica: a origem etnia, a religião, opinião política e filosófica. E de formas biológica: dados genéticos e biométricos, dados sobre a saúde e vida sexual.

A LGPD dar aos titulares dos dados pessoais o direito de administrar e solicitar aos detentores de seus dados armazenados o acesso, a correção, a eliminação de dados tratados em desconformidade com a LGPD e o bloqueio das informações em qualquer tempo.

A autodeterminação informativa é um instituto jurídico de caráter subjetivo e autônomo que também é consagrado na lei de proteção de dados pessoais da Europa. No Brasil, os doutrinadores demonstram divergência em distingui-lo em princípio ou em direito, o fato é que é um elemento de privacidade (MENDONÇA, 2014). Esse instituto jurídico ganhou maior destaque por razões de acúmulo de informações de dados pessoais 
dos usuários das tecnologias virando moeda entre empresa ou até mesmo pelo governo sem o conhecimento do titular dos dados gerando riqueza para empresas.

Na LGPD é elencado como um dos fundamentos da proteção de dados, de forma a dar o poder de escolha, ou seja, a liberdade do titular de escolher se seus dados passaram pelo tratamento de coleta, armazenamento e divulgação. Tempetino, Frazão e Oliva (2019) associa a autodeterminação informativa como o consentimento que segundo o autor é compreendido com uma liberdade de escolha, o consentimento.

O consentimento é demonstração da vontade que deve ser livre, clara e informada pelo titular que "concorda com o tratamento de dados pessoais com uma determinada finalidade" (BRASIL, LEI № 13.709/2018 - LEI GERAL DE PROTEÇÃO DE DADOS), sendo que a coleta do consentimento não é obrigatória ser escrita.

Outra questão muito comum que Tempetino, Frazão e Oliva (2019) retrata é a condição de ter acesso a determinados serviços e produtos na internet onde o usuário deve submeter ao tratamento de dados, ou seja, uma troca, o usuário fornece os seus dados pessoais e a empresa fornece os serviços. Neste caso a LGPD elenca os direitos no art.18 entre eles o de ter acesso aos dados, confirmação da existência, correção dos dados, o bloqueio, a revogação do consentimento.

Porém, a LGPD volta às pautas na casa legislativa em 2018, tendo seu texto aprovado com vigência somente após 2 anos. Em pleno ano do fim da vacitio legis, agosto de 2020 a LGPD é alvo de duas medidas provisória prorrogando o início de sua vigência, a última para maio de 2021 como a justificativa de medidas contra pandemia.

Entres as justificativas dadas pelos parlamentares é que as empresas precisam de segurança jurídica devido aos reflexos do isolamento social, ocasionado pela pandemia do novo coronavírus. Outro ponto, foi a não estruturação para funcionar de fato da Autoridade Nacional de Proteção de Dados (ANPD) o que dificultaria a aplicação das normas de proteção à privacidade e também a aplicação de sanções (DEMARTINI, 2020). 
Antes da pandemia, causada pelo covid-19, o país prévia o início da vigência da lei 13.709/18 para agosto de 2020. Contudo, não houve devida preparação estrutural, pois a lei PGDP estabelece a criação da Autoridade Nacional de Proteção de Dados que não saiu do papel. Essa instituição seria responsável pela fiscalização, edição de normas e aplicar sanções (MACHADO, 2019).

No decorrer da LGPD, artigo $4^{\circ}$, a lei elenca situações em que os dados pessoais não serão tratados com proteção da privacidade. Entre eles destacamos os dados pessoais coletados por particulares sem fins econômica e os dados pessoais coletados com a finalidade exclusiva de segurança pública e do Estado. Pois, nesta situação, o tratamento de dados é regido de forma que "prever medidas proporcionais e estritamente necessárias ao atendimento do interesse público, observados o devido processo legal, os princípios gerais de proteção e os direitos do titular previstos nesta Lei” (BRASIL, LEI № 13.709/2018 - LEI GERAL DE PROTEÇÃO DE DADOS).

A Constituição Cidadã que garantiu como direito fundamental à vida privada denominando forma de penalizações as violações tendo que indenizar os danos materiais e/ou morais sofridos. O respeito à vida privada mesmo sendo cláusula pétrea não é absoluto. Segundo, Barbosa e Silva (2019) diz que poderá ser relativizada caso seja um risco ao direito individual de terceiros ou o direito coletivo.

Ávila e Woloszyn (2019) discorre que o direito à privacidade e os dados de comunicações do indivíduo deve ser a flexibilizados quando a segurança nacional está em perigo. Mostrando que a ponderação e a relativização do sigilo de dados pessoais não devem estar acima do interesse público.

Em meio uma crise de saúde que reflete no desenvolvimento do país, o Brasil, vem procurando suavizar a pressão que o setor empresarial está sofrendo, devido a necessidade do isolamento social. O trabalho remoto foi a saída encontrada para amenizar a situação, porém esse tipo de trabalho carece de processo que garanta a segurança e a inviolabilidade de forma correta e adequada (FREITAS, 2020). 
Até o momento o isolamento social é a melhor forma de prevenção sendo essa medida adotada no Brasil e nos demais países. Medeiros (2020) diz que "medidas de isolamento social devem ser avaliadas constantemente, pois, se forem suspensas antes do momento adequado teremos uma nova onda, com crescimento dos casos de infecção".

O isolamento social mudou o comportamento e hábitos das pessoas, tendo que trabalhar e estudar em casa e por meio digitais, trazendo ao brasileiro um aumento de contatos como instrumentos oferecidos pela internet como aplicativos, sites entre outros.

O aumento do uso da internet, na pandemia, deixa o assunto ainda mais relevante a necessidade de estabelecer uma cultura de privacidade, já que o fluxo de comunicação digital se tornou uma necessidade de primeira linha na vida das pessoas.

O relatório da Google não divulga qualquer identificação individual e que foi desenvolvido como o objetivo de "fornecer informações sobre o que mudou em resposta às políticas destinadas a combater o COVID-19" (GOOGLE, 2020). Esse relatório podemos observar a movimentação e aglomeração de pessoas em determinado lugares e segundo a empresa não será disponibilizado informações privada.

Como o estado de calamidade o Poder Executivo através de medida provisória de $\mathrm{n}^{\circ}$ 954 de 17 de abril de 2020, estabelece que a prestadora de serviços de telefonia compartilhe dados de clientes com a Instituto Brasileiro de Geografia e Estatística IBGE, durante a situação emergencial provocado pelo coronavírus.

Porém em julgamento da Ação Direta de Inconstitucionalidade de $\mathrm{n}{ }^{\circ} 6.387$, decidiuse a suspensão da medida provisória de $n^{\circ}$ 954, onde argumentou "a fim de prevenir danos irreparáveis à intimidade e ao sigilo da vida privada de mais de uma centena de milhão de usuários dos serviços de telefonia fixa e móvel" (BRASIL, 2020, p12). 


\section{CONSIDERAÇÕES FINAIS}

Diante do exposto sobre a Lei de Proteção de Dados Pessoais observou-se que o respeito à privacidade não é um direito fundamental absoluto, pois existem situações que a coletividade fala mais alto que direito individual. Porém, é de extrema relevância que os direitos fundamentais sejam respeitados e protegidos por legislação e que se estabeleça uma cultura de proteção de dados pessoais e dados de saúde no Brasil para que episódio de vazamento de dados de saúde ocorrido em 2017 não aconteçam ou que sejam atribuídos punibilidade aos responsáveis.

Todavia, foi analisado uma celeuma entre medidas provisórias, decisões do STF quanto a disponibilização de dados pessoais, onde autoridade executiva determinou que empresas de telefonia compartilhassem dados pessoais dos seus clientes como o IBGE. Tal medida foi suspensa como a justificativa do direito ao sigilo dos indivíduos.

Em meio a calamidade pública, provocada pelo covid-19 o brasileiro buscou a internet como instrumento de trabalho, de estudos e como meio de comunicação fazendo como que pessoa tivesse mais contato como aplicativos e assim inserido informações importantes sobre sua vida sem a segurança que a lei de proteção de dados pessoais traria se estivesse em vigência.

A LGPD em seu texto jurídico deixa claro a intenção de aumentar a segurança de dados confidenciais onde dados clínicos devem ser compartilhados entre hospitais, clínicas e laboratórios somente com o consentimento do paciente. E caso, seja autorizado os dados devem ser criptografados, tal exigência da lei, exigem uma estruturação de equipamentos que ainda é precária.

Portanto, sem a vigência da LGPD podemos observar que o respeito à privacidade dos dados pessoais e dos dados de saúde são objeto de debate, pois o embate entre o direito à privacidade e a publicação de dados pessoais ainda é passível de estudos, principalmente em meio pandemia, mesmo com legislações assegurando a relativização. 


\section{REFERÊNCIAS}

AVILA, Ana Paula Oliveira; WOLOSZYN, André Luis. A tutela jurídica da privacidade e do sigilo na era digital: doutrina, legislação e jurisprudência. Rev. Investig.

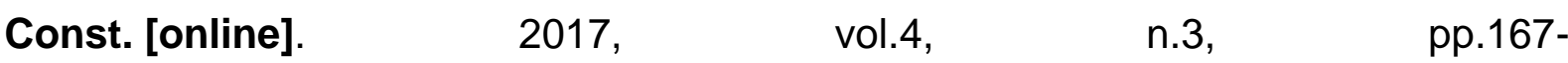
200. Disponível: https://doi.org/10.5380/rinc.v4i3.51295. Acesso: 30 de abr. de 2020.

BARBOSA, Danilo Ricardo Ferreira; SILVA. Carlos Sérgio Gurgel da. A coleta e o uso indevido de dados pessoais: um panorama sobre a tutela da privacidade no brasil e a lei geral de proteção de dados, $\boldsymbol{R} \boldsymbol{J} L \boldsymbol{B}, \mathrm{n}^{\circ}=6,2019$.

BRASIL. Constituição da República Federativa do Brasil de 1988. Brasília, DF: Presidência da República, 2016. Disponível em: http://www.planalto.gov.br/ccivil_03/constituicao/constituicao.htm. Acesso: 20 de abr. de 2020.

BRASIL. Constituição da República Federativa do Brasil de 1891. Brasília, DF: Presidência da República, 1891. Disponível em http://www.planalto.gov.br/ccivil_03/Constituicao/Constituicao91.htm. Acesso: 22 de abr. de 2020.

BRASIL. Lei no 13.709, de 14 de agosto de 2018. Lei Geral de Proteção de Dados Pessoais (LGPD). Lei Geral de Proteção de Dados Pessoais (LGPD). , Brasília, 2018.Disponível em:http://www.planalto.gov.br/ccivil_03/_ato20152018/2018/lei/L13709.htm. Acesso: 30 de março de 2020.

BRASIL. Medida provisória o 959, de 29 de março de 2020. Estabelece a operacionalização do pagamento do Benefício Emergencial de Preservação do Emprego e da Renda e do benefício emergencial mensal de que trata a Medida Provisória $\mathrm{n}^{\circ}$ 936, de 1ํ de abril de 2020, e prorroga a vacatio legis da Lei ํㅜ 13.709 , de 14 de agosto de 2018, que estabelece a Lei Geral de Proteção de Dados Pessoais - LGPD. Brasília. Disponível em: http://www.planalto.gov.br/ccivil_03/_ato20192022/2020/Mpv/mpv959.htm. Acesso: 15 de abr. de 2020. 
BRASIL. Supremo Tribunal Federal. Medida Cautelar $\mathrm{Na}$ Ação Direta De Inconstitucionalidade 6.387. Brasília. Relator: Juíza Rosa Weber. Distrito FEDERAL. 24 de abr. 2020.2 de Disponível: http://www.stf.jus.br/arquivo/cms/noticiaNoticiaStf/anexo/ADI6357MC.pdf. Acesso em 9 de maio de 2020.

BRASIL. Decreto $n^{\circ} n^{\circ}$ 6, de 20 de março de 2020. Reconhece, para os fins do art. 65 da Lei Complementar oㅜ 101, de 4 de maio de 2000, a ocorrência do estado de calamidade pública, nos termos da solicitação do Presidente da República encaminhada por meio da Mensagem no 93, de 18 de março de 2020. Brasília, 2020. Disponível em: http://www.planalto.gov.br/ccivil_03/portaria/DLG6-2020.htm. Acesso: 12de maio de 2020.

BOLESINA, luri; DIAS, Felipe da Veiga. Direito à Proteção de Dados Pessoais No Brasil E Os Traços Centrais de Uma Autoridade Local De Proteção. E-Civitas Revista Científica do Curso de Direito do UNIBH - Belo Horizonte. Volume X, número 1. Disponível em: http://revistas.unibh.br/index.php/dcjpg/index Acesso: 30 de abr. de 2020.

DEMARTINI, Felipe. Senado aprova adiamento da LGPD para agosto de 2021. disponível em :https://canaltech.com.br/legislacao/senado-aprova-adiamento-daIgpd-para-agosto-de-2021-162863/ . Acesso em 20 de abr. de 2020.

FERRAZ JÚNIOR, T. S. Sigilo de dados: o direito à privacidade e os limites à função fiscalizadora do Estado. Revista da Faculdade de Direito, Universidade de São Paulo, v. 88, p. 439-459, 1 jan. 1993.

FREITAS, André Ricardo Ribas; NAPIMOGA, Marcelo; DONALISIO, Maria Rita. Análise da gravidade da pandemia de Covid-19. Epidemiol. Serv. Saúde, Brasília, v. 29, n. 2. Disponível em: http://www.scielo.br/scielo.php. Acesso: 13 de maio 2020.

FREITAS. Nelson Adriano de. A Lei Geral de Proteção de Dados e a pandemia do novo coronavírus.

Disponível

em: 
http://www.lemosassociados.com.br/publicacoes/direito-civil/a-lei-geral-de-protecaode-dados-e-a-pandemia-do-novo-coronavirus. Acesso: 08 de maio de 2020.

GOOGLE. Relatórios de mobilidade da comunidade. Disponível em: https://www.google.com/covid19/mobility. Acesso: 09/05/2020.

MACHADO, Meyer, Sendacz e Opice Advogados. Lei Federal 13.709/18: Medida Provisória 869/18 Lei De Proteção de Dados Pessoais. Disponível em: https://www.machadomeyer.com.br/images/publicacoes/PDFs/Lei_Protecao de Dados. Acesso: 18, abril. 2019.

MENDONÇA, Fernanda Graebin. O direito à autodeterminação informativa: a (de) necessidade de criação de um novo direito fundamental para proteção de dados pessoais no Brasil. XI Seminário Internacional de Demanda social e Políticas Publicas na sociedade contemporânea e VII Mostra de Trabalhos Jurídicos científico. Disponível em: https://online.unisc.br/acadnet/anais/index.php/sidspp/article/viewFile/11702/1571. Acesso: 04 de maio de 2020.

MEDEIROS, Eduardo Alexandrino Servolo. DESAFIOS PARA O ENFRENTAMENTO DA PANDEMIA COVID-19 EM HOSPITAIS UNIVERSITÁRIOS. Rev. paul. pediatr., São Paulo , v. 38. Disponível em <http://www.scielo.br/scielo.php?script=sci_arttext\&pid=S010305822020000100101\&lng=pt\&nrm=iso >. Acesso: 13 de maio de 2020.

SEVERINO, Joaquim Antônio. Metodologia do Trabalho Cientifico. São Paulo: Cortez editora, 2013.

TEMPETINO, Gustavo; FRAZÃO, Ana; OLIVA, Milena Donato. Lei Geral de Proteção de Dados Pessoais e suas repercussões no Direito Brasileiro: capítulo 10 Consentimento e proteção de dados pessoais na LGPD. Revista Dos Tribunais. 2019. Acesso: 28 de abr. de 2020. 
ZUMAS, Vytautas Silva Fabiano. Coronavírus, isolamento social e a Privacidade Diferencial. Disponível em: http://direitoeti.com.br/artigos/coronavirus-isolamentosocial-e-a-privacidade-diferencial/. Acesso: 28 de abr. de 2020.

Enviado: Julho, 2020.

Aprovado: Outubro, 2020. 